\title{
The effect of antibacterial agents on the production of nitric oxide induced by lipopolysaccharide in mice
}

\author{
Hampartsoum Barsoumian, Fadi El-Rami, Alexander M. Abdelnoor
}

Department of Microbiology \& Immunology, Faculty of Medicine, American University of Beirut, Beirut, Lebanon. Email: aanoor@aub.edu.lb

Received 10 March 2010; revised 20 March 2010; accepted 21 March 2010.

\begin{abstract}
Some antibacterial agents have been shown to neutralize the biological properties of bacterial lipopolysaccharide (LPS). The aim of this study was to elucidate the role of gentamicin, tobramycin, imipenem, tigecycline, and isoniazid in affecting the production of nitric oxide (NO) induced by LPS in mice. Groups of mice were injected intraperitoneally with LPS alone, antibacterial agent alone, or LPS in combination with an antibacterial agent. Serum NO levels were determined at 1, 3, 6 and 9 hours post-injection using the Griess reagent method. Thin layer chromatography was performed to determine if antibacterial agent-LPS interaction had occurred. All the antibacterial agents suppressed NO production. Moreover, LPS-induced production of NO was suppressed by all the antibacterial agents, tobramycin and tigecycline being the most effective at 9 hours post-injection. Blocking of any of the stages leading to NO production by the antibacterial agents is suggested. Moreover, thin layer chromatograms obtained are suggestive of LPS-antibacterial agent interactions.
\end{abstract}

Keywords: Lipopolysaccharide; Antibacterial Agents; Nitric Oxide; Mice

\section{INTRODUCTION}

Antibacterial agents have been widely used to treat infectious diseases. However, it has become apparent that antibacterial agents may also play a role in the pathophysiological process of septic shock, mainly through their ability to liberate immunologically and inflammatory active components such as lipopolysaccharide (LPS) from the cell wall of Gram negative bacteria [1].

It is well established that septic shock is in part mediated by inflammatory cytokines including tumor necrosis factor alpha (TNF- $\alpha$ ), interleukin-1 (IL-1), interleukin-6 (IL-6), and interleukin-12 (IL-12) as well as the excessive production of NO induced by LPS [2]. NO is synthesized by converting L-arginine to L-citrulline. The reaction is catalyzed by a family of nitric oxide synthase (NOS) enzymes. Three different NOS isoforms have been characterized; neuronal NOS (nNOS, NOS I), inducible NOS (iNOS, NOS II) and endothelial NOS (eNOS, NOS III). Among the three, iNOS is expressed in response to various inflammatory stimuli such as LPS and certain pro-inflammatory cytokines which conesquently generate a large amount of NO by macrophages, hepatocytes, vascular smooth muscles and cardiac myocytes [2].

A number of LPS-detoxifying agents including some antibacterial agents have been reported. Serum and fractions thereof have been reported to detoxify LPS [3-5]. Hydrogen peroxide [6], lithium aluminum hydride [7], boron trifluoride [8], and sodium deoxycholate $[9,10]$ are some of the agents that have been reported to detoxify LPS. It has been suggested that detoxification could be due to either binding to, or degrading LPS $[11,12]$. In an earlier study by AL-Shami et al. [13], it was shown that there was a decline in interferon- $\gamma$ and TNF- $\alpha$ levels in mice injected with LPS treated with either tobramycin or vancomycin. David et al. [14] reported that lipopolyamines which are essentially nontoxic compounds inhibit, in a dose-dependent manner, LPS-induced activation of the limulus clotting cascade and the production of TNF- $\alpha$, IL- 6 , and nitric oxide from LPS-stimulated J774.A1 cells, a murine macrophage-like cell line. Moore et al. [15] reported that polymyxin B, gentamicin and streptomycin bind to LPS and lipid A obtained from Pseudomonas aeruginosa and possibly sequester their activity. Moreover, various kinds of peptides have been developed that bind to, and neutralize the LPS effect in septic shock. Some of these peptides include $\alpha$-helical peptides such as magainin and cecropin. Other peptide families include bactenecins, gramicidins, defensins, saposins, and lactoferrins [16]. A more recent study by Zorko and Jerala shows that chlorhexidine and alexidine bind to lipopolysaccharide and lipoteichoic acid preventing their binding to Toll-like receptor 4 (TLR-4) and Toll-like receptor 2 (TLR-2) respectively, hence reduceing the NO produced by murine macrophages [17]. 
The aim of this study was to determine the effects of gentamicin, tobramycin, imipenem, tigecycline and isoniozid on the ability of LPS to induce the production of $\mathrm{NO}$ in mice.

\section{MATERIALS AND METHODS}

\subsection{Lipopolysaccharide (LPS) and Antibacterial Agents}

LPS from Salmonella enterica serovars Minnesota, was obtained from Sigma Chemicals Co., MO, USA. $30 \mu \mathrm{g} /$ $0.5 \mathrm{~mL}$ of an LPS suspension in pyrogen-free saline (confirmed by the Limulus Amebocyte Lysate Assay) was prepared.

Gentamicin sulphate, Tobramycin, Imipenem monohydrate and Isoniazid were obtained from Sigma-Aldrich, USA. Tigecycline was obtained from Wyeth Pharmaceuticals Inc., Philadelphia, USA. Dose of each antibacterial agent used alone or in combination with LPS is indicated in Table 1.

\subsection{Thin Layer Chromatography (TLC)}

The procedure described by Buttke and Ingram was followed [18]. Fluka silica plates backed on aluminum, with fluorescence, size: $10 \mathrm{~cm} \times 20 \mathrm{~cm}(0.2 \mathrm{~mm}$ thickness $)$ were used. The solvent (mobile phase) was a mixture of isobutyric acid, concentrated $\mathrm{NH}_{4} \mathrm{OH}$ and pyrogen-free water in a ratio of 57:4:39. Ten $\mu \mathrm{L}$ of each of the suspensions/solutions listed in Table 2 was applied to the plate. The plate was then placed in the vessel containing the

Table 1. Doses of LPS, antibacterial agent, and combination of LPS and antibacterial agent administered intraperitoneally to mice.

\begin{tabular}{cc}
\hline Group & Material Injected and Amount \\
\hline 1 & pyrogen-free saline, $0.5 \mathrm{~mL} / \mathrm{mouse}$ \\
2 & LPS, $30 \mu \mathrm{g} / 0.5 \mathrm{~mL}$ saline $/ \mathrm{mouse}$ \\
3 & gentamicin, $60 \mu \mathrm{g} / 0.5 \mathrm{~mL}$ saline $/ \mathrm{mouse}$ \\
4 & tobramycin, $120 / 0.5 \mathrm{saline} / \mathrm{mouse}$ \\
5 & imipenem, $10 \mu \mathrm{g} / 0.5 \mathrm{~mL}$ saline $/ \mathrm{mouse}$ \\
6 & tigecycline, $150 \mu \mathrm{g} / 0.5 \mathrm{~mL}$ saline $/ \mathrm{mouse}$ \\
7 & isoniazid, $150 \mu \mathrm{g} / 0.5 \mathrm{~mL}$ saline $/ \mathrm{mouse}$ \\
8 & LPS, $30 \mu \mathrm{g}+$ gentamicin, $60 \mu \mathrm{g} / 0.5 \mathrm{~mL}$ saline $/ \mathrm{mouse}$ \\
9 & LPS, $30 \mu \mathrm{g}+$ tobramycin, $120 \mu \mathrm{g} / 0.5 \mathrm{~mL}$ saline $/ \mathrm{mouse}$ \\
10 & LPS, $30 \mu \mathrm{g}+$ imipenem, $10 \mu \mathrm{g} / 0.5 \mathrm{~mL}$ saline $/ \mathrm{mouse}$ \\
11 & LPS, $30 \mu \mathrm{g}+$ tigecycline, $150 \mu \mathrm{g} / 0.5 \mathrm{~mL}$ saline $/ \mathrm{mouse}$ \\
12 & LPS, $30 \mu \mathrm{g}+$ isoniazid, $150 \mu \mathrm{g} / 0.5 \mathrm{~mL}$ saline $/ \mathrm{mouse}$ \\
\hline
\end{tabular}

Table 2. LPS and Antibacterial Agent Suspensions used in Thin layer Chromatography.

$\mathrm{LPS}, 20 \mu \mathrm{g} / 10 \mu \mathrm{L}$ saline
Gentamicin; $40 \mu \mathrm{g} / 10 \mu \mathrm{L}$ saline
$40 \mu \mathrm{g}$ Gentamicin $+20 \mu \mathrm{g} \mathrm{LPS} / 10 \mu \mathrm{L}$ saline
Isoniazid; $50 \mu \mathrm{g} / 10 \mu \mathrm{L}$ saline
$50 \mu \mathrm{g}$ Isoniazid $+20 \mu \mathrm{g} \mathrm{LPS} / 10 \mu \mathrm{L}$ saline
Tigecycline; $100 \mu \mathrm{g} / 10 \mu \mathrm{L}$ saline
$100 \mu \mathrm{g}$ Tigecycline $+20 \mu \mathrm{g}$ LPS $/ 10 \mu \mathrm{L}$ saline
Imipenem; $12 \mu \mathrm{g} / 10 \mu \mathrm{L}$ saline
$12 \mu \mathrm{g}$ Imipenem $+20 \mu \mathrm{g} \mathrm{LPS} / 10 \mu \mathrm{L}$ saline
Tobramycin; $80 \mu \mathrm{g} / 10 \mu \mathrm{L}$ saline
$80 \mu \mathrm{g}$ Tobramycin $+20 \mu \mathrm{g} \mathrm{LPS} / 10 \mu \mathrm{L}$ saline

Plates were loaded with $10 \mu \mathrm{L}$ of each suspension.

solvent (mobile phase). The mobile phase was allowed to ascend the plate for a period of 6 hours. The plate was dried and ultraviolet light was used to observe and mark the bands obtained. Retention Factors $\left(\mathrm{R}_{\mathrm{f}}\right)$ were calculated by dividing the distance migrated by the band by the distance migrated by the solvent front.

\subsection{Mice}

Female BALB/c mice aged 6 weeks (weight range: 24-26 g) were obtained from the animal care facility at the American University of Beirut Faculty of Medicine. Mice were treated and sacrificed in accordance to the ethical policies.

Twelve groups, each containing 12 mice were used. They were injected intraperitoneally with pyrogen-free saline, LPS alone, antibacterial agent alone, or a combination of LPS and antibacterial agent (Table 1). Three mice from each group were bled by cardiac puncture at 1 , 3,6 and 9 hours post-injection. Timings were deduced from the work of Terao et al. [19]. In addition, a group of three mice that received nothing was also sacrificed to measure the basic physiological NO concentration. Prior to bleeding, mice were anesthetized with a $0.5 \mathrm{~mL}$ mixture of $0.12 \mathrm{~mL}$ ketamine $(50 \mathrm{mg} / \mathrm{mL}), 0.03 \mathrm{~mL}$ xylazine $(20 \mathrm{mg} / \mathrm{mL})$, and $0.35 \mathrm{~mL}$ pyrogen-free water [20]. Blood from each group was collected; serum was separated and used for NO determination.

\subsection{Nitric Oxide (NO) Quantification}

Griess Reagent system (Fluka Nitrate/Nitrite assay kit, Sigma-Aldrich, USA) was used to measure the amount of NO in the mice sera. The procedure described by the manufacturer was followed. In this method NO is converted to nitrate and nitrite. The nitrate produced is then 
converted to nitrite and the total amount of nitrite produced is determined. Each serum specimen was tested in duplicate and the mean and standard deviation reported. Percents change of serum NO levels in the different groups that received antibacterial agent alone were calculated by subtracting the NO level obtained when antibacterial agent alone was given from the basic NO level obtained when nothing was injected. The difference was divided by the basic NO value and multiplied by 100 . Percents change of serum NO levels in the different groups that received a combination of LPS and antibacterial agent were calculated by subtracting the concentration of NO obtained when a combination of LPS and antibacterial agent was used from the NO value obtained when LPS alone was injected. The difference was divided by the LPS-alone value and multiplied by 100 .

\section{RESULTS}

\subsection{Thin Layer Chromatography}

It can be observed in Table 3 and Figure 1 that there was a slight change in the $\mathrm{R}_{\mathrm{f}}$ value and the appearance of tailing when LPS was treated with gentamicin. Only tailing with no apparent bands was obtained upon treatment of LPS with tobramycin. A single band with slight differences in $R_{f}$ values were obtained when LPS was treated with the other antibacterial agents. In addition, there were differences in the shape and intensity of the bands.

\subsection{Nitric Oxide Levels}

The serum nitric oxide levels obtained in the different groups of mice at different time intervals are given in Table 4. The percent change in NO levels in mice that received an antibacterial agent or LPS combined with an antibacterial agent are given in Table 5. It can be observed that at 1 and 3 hours post-injection, LPS alone caused a decrease in serum NO levels followed by increased levels at 6 and 9 hours post-injection. In all cases where antibacterial agent alone was administered there was a decline in NO levels. In most cases where mice were injected with a combination of antibacterial agent and LPS, there was a decline in serum NO levels when compared to levels obtained in mice that received LPS alone. The most pronounced decline was in the groups that received LPS combined with tobramycin or tigecycline at 9 hours post-injection.

\section{DISCUSSION}

LPS has a broad spectrum of biological activity. It activates the complement and coagulation systems and interacts with the TLR-4. As a result, a number of biologically active substances are produced in excess, and might lead to disseminated intravascular coagulation, hypotension and shock [2]. It has been suggested that antibacterial agents used to treat Gram negative infec-
Table 3. Retention Factors $\left(\mathrm{R}_{\mathrm{f}}\right)$ of the Different Bands Obtained in Thin Layer Chromatography.

\begin{tabular}{cc}
\hline Preparation & $\mathrm{R}_{\mathrm{f}}$ \\
\hline LPS & 0.68 \\
Gentamicin & 0.63 \\
Gentamicin + LPS & 0.60 , Tailing \\
Tobramycin & Tailing, no visible band \\
Tobramycin + LPS & Tailing, no visible band \\
Imipenem & 0.71 \\
Imipenem + LPS & 0.69 \\
Isoniazid & 0.79 \\
Isoniazid + LPS & 0.79 \\
Tigecycline & 0.74 \\
Tigecycline + LPS & 0.71 \\
\hline
\end{tabular}

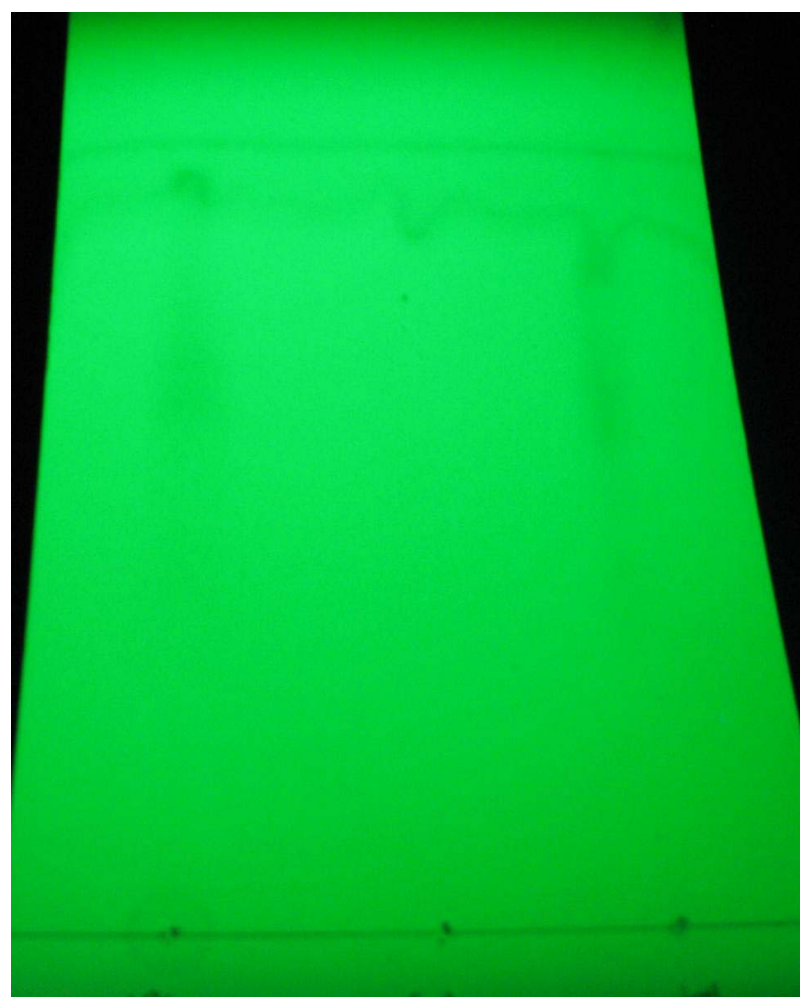

From left to right:

LPS spot: $10 \mu \mathrm{L}$ containing $20 \mu \mathrm{g}$ LPS was applied.

Gentamicin spot: $10 \mu \mathrm{L}$ containing $40 \mu \mathrm{g}$ gentamicin was applied.

LPS + Gentamicin spot: $10 \mu \mathrm{L}$ containing $20 \mu \mathrm{g}$ LPS $+40 \mu \mathrm{g}$ getamicin was applied. Note the tailing obtained.

$\mathrm{R}_{\mathrm{f}} \mathrm{LPS}=0.68 ; \mathrm{R}_{\mathrm{f}}$ Gentamicin $=0.63 ; \mathrm{R}_{\mathrm{f}} \mathrm{LPS}+$ Gentamicin $=0.6$

Figure 1. A representative thin layer chromatogram.

tions may promote the release of LPS and contribute to transient exacerbation of clinical symptoms $[1,21]$. On 
Table 4. Serum Nitric Oxide Levels in Mice Treated with LPS, Antibacterial Agent, or LPS + Antibacterial Agent at Different Time Intervals Post-injection.

\begin{tabular}{|c|c|c|c|c|}
\hline \multirow[t]{2}{*}{ Treatment } & \multicolumn{4}{|c|}{ Nitric Oxide Level $(\mu \mathrm{M})$ Post-Treatment at } \\
\hline & 1 hour & 3 hour & 6 hour & 9 hour \\
\hline Saline & $198.4 \pm 16.8$ & $200.9 \pm 16.9$ & $201.9 \pm 17.2$ & $202.4 \pm 17.1$ \\
\hline LPS & $106.4 \pm 43.6$ & $99.1 \pm 23.9$ & $305.1 \pm 49.8$ & $454.3 \pm 78.6$ \\
\hline Gentamicin & $58.0 \pm 14.7$ & $117.7 \pm 20.0$ & $106.7 \pm 21.0$ & $58.3 \pm 17.2$ \\
\hline Imipenem & $53.2 \pm 34.0$ & $54.1 \pm 30.0$ & $69.3 \pm 17.6$ & $73.8 \pm 21.7$ \\
\hline Isoniazid & $46.7 \pm 10.7$ & $64.1 \pm 19.9$ & $44.8 \pm 15.0$ & $59.6 \pm 19.2$ \\
\hline Tigecycline & $50.5 \pm 10.6$ & $45.8 \pm 13.0$ & $61.9 \pm 20.8$ & $54.7 \pm 21.4$ \\
\hline Tobramycin & $47.5 \pm 5.9$ & $44.7 \pm 8.9$ & $32.8 \pm 6.4$ & $49.1 \pm 6.7$ \\
\hline LPS + Gentamicin & $69.0 \pm 14.0$ & $103.1 \pm 19.2$ & $371.4 \pm 77.0$ & $261.2 \pm 51.1$ \\
\hline LPS + Imipenem & $63.1 \pm 15.6$ & $101.0 \pm 21.0$ & $145.1 \pm 29.4$ & $275.4 \pm 59.1$ \\
\hline LPS + Isoniazid & $84.2 \pm 18.6$ & $78.6 \pm 17.4$ & $263.8 \pm 53.8$ & $239.6 \pm 71.1$ \\
\hline LPS + Tigecycline & $46.6 \pm 5.7$ & $73.4 \pm 7.0$ & $194.6 \pm 25.0$ & $145.9 \pm 13.3$ \\
\hline LPS + Tobramycin & $53.8 \pm 11.9$ & $66.0 \pm 19.8$ & $134.6 \pm 21.4$ & $107.5 \pm 16.6$ \\
\hline
\end{tabular}

A group of 3 mice received nothing and the basic NO concentration obtained was $196.4 \pm 19.2 \mu \mathrm{M}$. comparing this result with values obtained for saline alone, we can deduce that there is almost no difference in the values of both. So injecting saline alone has insignificant or no effect on nitric oxide levels and it can be used safely as a solvent.

Table 5. Percent change in Serum Nitric Oxide Levels in Mice Injected with an Antibacterial Agent or a Combination of LPS and Antibacterial Agent at Different Time Intervals Post-Injection.

\begin{tabular}{|c|c|c|c|c|}
\hline \multirow[t]{2}{*}{ Treatment } & \multicolumn{4}{|c|}{ Percent change Post-treatment at } \\
\hline & 1 hour & 3 hour & 6 hour & 9 hour \\
\hline Gentamicin & $-70.5 \%$ & $-40.1 \%$ & $-45.7 \%$ & $-70.3 \%$ \\
\hline Imipenem & $-72.9 \%$ & $-72.4 \%$ & $-64.7 \%$ & $-62.4 \%$ \\
\hline Isoniazid & $-76.2 \%$ & $-67.3 \%$ & $-77.2 \%$ & $-69.6 \%$ \\
\hline Tigecycline & $-74.3 \%$ & $-76.7 \%$ & $-68.5 \%$ & $-72.2 \%$ \\
\hline Tobramycin & $-75.8 \%$ & $-77.2 \%$ & $-83.3 \%$ & $-75.0 \%$ \\
\hline LPS + Gentamicin & $-35.2 \%$ & $0 \%$ & $0 \%$ & $-42.5 \%$ \\
\hline LPS + Imipenem & $-40.7 \%$ & $0 \%$ & $-52.4 \%$ & $-39.4 \%$ \\
\hline LPS + Isoniazid & $-20.9 \%$ & $-20.7 \%$ & $-13.5 \%$ & $-47.3 \%$ \\
\hline LPS + Tigecycline & $-56.2 \%$ & $-26.0 \%$ & $-36.2 \%$ & $-67.9 \%$ \\
\hline LPS + Tobramycin & $-49.4 \%$ & $-33.4 \%$ & $-55.9 \%$ & $-76.3 \%$ \\
\hline
\end{tabular}

(-) sign represents a decline in NO level

the other hand there are reports indicating that some antibacterial agents have an anti-inflammatory effect, in addition to their anti-bacterial effect [22-27].

In this study the effect of 4 antibacterial agents that are usually used to treat Gram negative infections, and isoniazid used to treat tuberculosis, on the production of
NO induced by LPS in mice was investigated. In all cases the antibacterial agent reduced the amount of NO induced by LPS.

LPS is a TLR-4 ligand. LPS first binds to serum Lipid Binding Protein (LBP) which in turn binds to CD14 expressed by dendritic cells, macrophages and other cell 
types, and finally the complex interacts with TLR4/MD2 [28]. Intracellular signals are then transduced through the, MyD88 dependent and independent pathways. In the MyD88 dependant pathway, a series of reactions involving MyD88, interleukin-1 (IL-1) receptor-associated kinase (IRAK) and TNF (tumor necrosis factor)- $\alpha$ receptorassociated factor 6 (TRAF6) will lead to the activation of nuclear factor kappa B (NF-kB). This in turn activates gene expression and causes the production and release of inflammatory mediators including the cytokines TNF- $\alpha$, IL-1, IL-6 and IL-12 [29].

In the MyD88 independent pathway or TRIF [TIR (Toll/interleukin-1 receptor) domain-containing adaptor protein inducing interferon beta] pathway, the interferon regulatory factor 3 (IRF3) is activated initially, resulting in the production of INF- $\alpha$, INF- $\beta$ and NO, later NF-kB is activated as well [30]. On the other hand, antibacterial agents could suppress NO production by suppressing gamma interferon production. LPS induces the production of cytokines such as gamma interferon and tumor necrosis factor. When gamma interferon engages its receptor expressed by cells such as macrophages the signaling pathway results in activation of the transcription factor, IRF-1 and the production of iNOS. In an earlier study by Al-Shami et al. it was reported that tobramycin and vancomycin suppressed the production of gamma interferon and tumor necrosis factor induced by LPS [13].

Antibacterial agents might have an anti-inflammatory effect by blocking any one of the stages leading to the production of NO induced by LPS. The fact that all 5 antibacterial agents studied caused a decrease in NO levels and suppressed the NO-producing effect of LPS is in support of their anti-inflammatory property.

Another potential property of antibacterial agents is their ability to bind to LPS and sequester its activity. LPS consists of an O-polysaccharide side chain, a core polysaccharide, and a lipid A which is the main biologically active part of the molecule. Lipid A in itself is a phosphoglycolipid made up of $\beta(1,6)$ disaccharide glucoseamine backbone that contains $\alpha$-glycosidic and non-glycosidic phosphoryl groups in the 1 and 4' positions, and (R)-3-hydroxy fatty acids in ester and amide linkages. The disaccharide backbone is believed to be involved in binding to cell receptors and the fatty acid chains are thought to activate the cells following binding [13]. Gentamicin, tobramycin, imipenem, isoniazid, and tigecycline are rich in reactive amide and hydroxyl groups. It could be hypothesized that the antibacterial agents investigated bind to the lipid A portion, possibly to the ester and amide linkages of the fatty acid chains, and alter the bioactivity of LPS, leading to decreased activation of cells expressing TLR-4 and less NO production. The thin layer chromatograms obtained are in support of this hypothesis. Thin layer chromatograms re- vealed changes in $R_{f}$ values, appearance of tailing, and differences in the shape and intensity of the bands when LPS alone was compared to LPS treated with antibacterial agent. Tailing could be the result of decomposition, or due to some ionization of the acidic or basic groups in the chemical structure of one or more of the components in the sample [31]. Moreover, Moore et al. [15] proved that polycationic aminoglycosides such as gentimicin and streptomycin can displace dansyl polymyxin in binding to LPS and lipid A.

Isoniazid (isonicotinic acid hydrazide) (INH), is usually used to treat tuberculosis, and not Gram negative infections. It prevents the synthesis of mycolic acid, a constituent of the cell wall of Mycobacterium tuberculosis [32]. Because of its cationic nature it was assumed that it would bind to LPS and neutralize its effect. The results supported this assumption and it is proposed to use isoniazid in conjunction with other antibacterial agents for treating Gram negative infections in situations where exacerbation of clinical symptoms are anticipated as a result of LPS release.

It is worth noting that LPS when given alone resulted in a decrease in NO production at 1 and 3 hours, followed by an increase at 6 and 9 hours post-injection. Rehan et al. [33] reported that LPS affected the production of pro-inflammatory cytokines in a time-dependent manner. At 6 hours post-treatment there was an increase, and at 72 hours a decrease in pro-inflammatory markers. Behling and Nowotny [34] and Haas et al. [35] have reported a time-dependent effect related to the adjuvant action of LPS and its derivatives. Depending on the time interval between the administration of antigen and LPS, either immunosuppression or immune enhancement was observed. Reasons for this so-called oscillating effect is not known, but it has been hypothesized that immunosuppression and immune enhancement might be under different genetic control, or the action of LPS on cells in accordance to their stage of development.

In conclusion, the antibacterial agents tested suppressed the production of NO induced by LPS. It appears that two mechanisms might be involved; they bind to LPS and block its action, and/or they interfere with pathways leading to NO production.

\section{ACKNOWLEDGEMENTS}

This study was supported by funds from the Faculty of Medicine, American University of Beirut.

\section{REFERENCES}

[1] Lepper, P.M., Held, T.K., Schneider, E.M., Bolke, E., Gerlach, H. and Trautmann, M. (2002) Clinical implications of antibiotic-induced endotoxin release in septic shock. Intensive Care Medicine, 28(7), 824-833.

[2] Parratt, J.R. (1998) Nitric oxide in sepsis and endotoxaemia. Journal of Antimicrobial Chemotherapy, 41(1), 
31-39.

[3] Hegemann, F. and Lessmann, H. (1958) Nature of the pyrogen-neutralizing factor in human blood. V. occurrence of the endotoxinneutralizing serum factor in various animal species. Zeitschrift Für Immunitatsforschung Und Experimentelle Therapie, 115(5), 391-401.

[4] Stauch, J.E. and Johnson, A.G. (1959) The alteration of bacterial endotoxins by human and rabbit serum. Journal of Immunology, 82, 252-263.

[5] Abdelnoor, A.M., Harvie N.R. and Johnson A.G. (1982) Neutralization of bacteria-and endotoxin-induced hypotension by lipoprotein-free human serum. Infection and Immunity, 38(1), 157-161.

[6] Cherkin, A. (1975) Destruction of bacterial endotoxin pyrogenicity by hydrogen peroxide. Immunochemistry, 12(6-7), 625-627.

[7] Noll, H. and Braude, A.I. (1961) Preparation and biological properties of a chemically modified escherichia coli endotoxin of high immunogenic potency and low toxicity. Journal of Clinical Investigation, 40(11), 1935-1951.

[8] Nowotny, A. (1963) Endotoxoid preparations. Nature, 197(4868), 721-722.

[9] Ribi, E., Anacker, R.L., Brown, R., Haskins, W.T., Malmgren, B., Milner, K.C., et al. (1966) Reaction of endotoxin and surfactants. I. physical and biological properties of endotoxin treated with sodium deoxycholate. Journal of Bacteriology, 92(5), 1493-1509.

[10] Tarmina, D.F., Milner, K.C., Ribi, E. and Rudbach, J.A. (1968) Reaction of endotoxin and surfactants. II. Immunologic properties of endotoxins treated with sodium deoxycholate. Journal of Immunology, 100(2), 444-450.

[11] Keene, W.R., Landy, M. and Shear, M.J. (1961) Inactivation of endotoxin by a humoral component. VII. enzymatic degradation of endotoxin by blood plasma. Journal of Clinical Investigation, 40, 302-310.

[12] Yoshioka, M. and Johnson, A.G. (1962) Characteristics of endotoxin altering fractions derived from normal human serum. Journal of Immunology, 89, 326-335.

[13] Al-Shami, A.K., Itani, L.Y., Skaff, N.N., Haddad, E.K., Abdelnoor, A.M. (1995) Effects of acetyl salicylic acid, tobramycin and vancomycin on some biological activities of endotoxin. EOS Rivista di Immunologia ed Immunofarmacologia, 15, 71-75.

[14] David, S.A., Silverstein, R., Amura, C.R., Kielian, T. and Morrison, D.C. (1999) Lipopolyamines: Novel antiendotoxin compounds that reduce mortality in experimental sepsis caused by gram-negative bacteria. Antimicrobial Agents \& Chemotherapy, 43(4), 912-919.

[15] Moore, R.A., Bates, N.C. and Hancock, R.E. (1986) Interaction of polycationic antibiotics with pseudomonas aeruginosa lipopolysaccharide and lipid A studied by using dansyl-polymyxin. Antimicrobial Agents \& Chemotherapy, 29(3), 496-500.

[16] Jerala, R. and Porro, M. (2004) Endotoxin neutralizing peptides. Current Topics in Medicinal Chemistry, 4(11), 1173-1184.

[17] Zorko, M. and Jerala, R. (2008) Alexidine and chlorhexidine bind to lipopolysaccharide and lipoteichoic acid and prevent cell activation by antibiotics. Journal of Antimicrobial Chemotherapy, 62(4), 730-737.

[18] Buttke, T.M. and Ingram, L.O. (1975) Comparison of lipopolysaccharides from agmenellum quadruplicatum to escherichia coli and salmonella typhimurium by using thin-layer chromatography. Journal of Bacteriology, 124(3), 1566-1573.

[19] Terao, H., Asano, K., Kanai, K., Kyo, Y., Watanabe, S., Hisamitsu, T., et al. (2003) Suppressive activity of macrolide antibiotics on nitric oxide production by lipopolysaccharide stimulation in mice. Mediators of Inflammation, 12(4), 195-202.

[20] Moreira, A.L., Wang, J., Sarno, E.N. and Kaplan, G. (1997) Thalidomide protects mice against LPS-induced shock. Brazilian Journal of Medical \& Biological Research, 30(10), 1199-1207.

[21] Kusser, W.C. and Ishiguro, E.E. (1988) Effects of aminoglycosides and spectinomycin on the synthesis and release of lipopolysaccharide by escherichia coli. Antimicrobial Agents \& Chemotherapy, 32(8), 1247-1250.

[22] Sugiyama, K., Shirai, R., Mukae, H., Ishimoto, H., Nagata, T., Sakamoto, N., et al. (2007) Differing effects of clarithromycin and azithromycin on cytokine production by murine dendritic cells. Clinical \& Experimental Immunology, 147(3), 540-546.

[23] Kaushik V., Beduya D., Kalampokis I., Kohlhoff, S., O Joks R., G Durkin H. and Nowakowski M. (2007) Tetracyclines tigecycline and doxycycline inhibit LPS-induced nitric oxide production by RAW 264.7 murine macrophages. Journal of Immunology, 178, (101)1-7.

[24] Cazalis, J., Bodet, C., Gagnon, G. and Grenier, D. (2008) Doxycycline reduces lipopolysaccharide-induced inflammatory mediator secretion in macrophage and ex vivo human whole blood models. Journal of Periodontology, 79(9), 1762-1768.

[25] Yang, L.P., Zhu, X.A. and Tso, M.O. (2007) Minocycline and sulforaphane inhibited lipopolysaccharide-mediated retinal microglial activation. Molecular Vision, 13, 10831093.

[26] Henry, C.J., Huang, Y., Wynne, A., Hanke, M., Himler, J., Bailey, M.T., et al. (2008) Minocycline attenuates lipopolysaccharide (LPS)-induced neuroinflammation, sickness behavior, and anhedonia. Journal of Neuroinflammation, 5, (15)1-14.

[27] Eswarappa, S.M., Basu, N., Joy, O. and Chakravortty, D. (2008) Folimycin (concanamycin A) inhibits LPS-induced nitric oxide production and reduces surface localization of TLR4 in murine macrophages. Innate Immunity, 14(1), 13-24.

[28] He, H., Genovese, K.J., Nisbet, D.J. and Kogut, M.H. (2006) Involvement of phosphatidylinositol-phospholipase $\mathrm{C}$ in immune response to salmonella lipopolysacharide in chicken macrophage cells (HD11). International Immunopharmacology, 6(12), 1780-1787.

[29] Yamamoto, M., Sato, S., Hemmi, H., Sanjo, H., Uematsu, S., Kaisho, T., et al. (2002) Essential role for TIRAP in activation of the signalling cascade shared by TLR2 and TLR4. Nature, 420, 324-329.

[30] Bagchi, A., Herrup, E.A., Warren, H.S., Trigilio, J., Shin, H.S., Valentine, C., et al. (2007) MyD88-dependent and MyD88-independent pathways in synergy, priming, and tolerance between TLR agonists. Journal of Immunology, 178, 1164-1171.

[31] Rabel, F. (2009) Reviving Thin Layer Chromatography. Chromatography Techniques. http://www.laboratoryequipment.com/article-reviving-thi 
n-layer-chromatography.aspx

[32] Timmins, G.S. and Deretic, V. (2006) Mechanisms of action of isoniazid. Molecular Microbiology, 62(5), 12201227.

[33] Rehan, V.K., Dargan-Batra, S.K., Wang, Y., Cerny, L., Sakurai, R., Santos, J., et al. (2007) A paradoxical temporal response of the PTHrP/PPARgamma signaling pathway to lipopolysaccharide in an in vitro model of the developing rat lung. American Journal of Physiology.
Lung Cellular and Molecular Physiology, 293(1), 182-190.

[34] Behling, U.H. and Nowotny, A. (1977) Immune adjuvancy of lipopolysaccharide and a nontoxic hydrolytic product demonstrating oscillating effects with time. Journal of Immunology, 118, 1905-1907.

[35] Haas, G.P., Johnson, A.G. and Nowotny, A. (1978) Suppression of the immune response in $\mathrm{C} 3 \mathrm{H} / \mathrm{HeJ}$ mice by protein-free lipopolysaccharides. Journal of Experimental Medicine, 148(4), 1081-1086. 